\title{
ASPIRAÇÕES E TEMORES DE JOVENS EMPREENDEDORES
}

\section{ASPIRATIONS AND FEARS OF YOUNG ENTREPRENEURS}

William Nunes da Silva

Universidade Municipal de São Caetano do Sul - USCS

São Caetano do Sul, SP, Brasil

E-mail: geanppoliveira@hotmail.com

\section{Aline Crespo}

Universidade Municipal de São Caetano do Sul - USCS

São Caetano do Sul, SP, Brasil

E-mail: alinecrespo@uscs.edu.br

Antônio Carlos Gil

Professor do Programa de Pós-Graduação em Administração da Universidade Municipal de São Caetano do Sul - USCS

São Caetano do Sul, SP, Brasil

E-mail: geanppoliveira@hotmail.com

\section{RESUMO}

Esta pesquisa tem como objetivo explorar a compreensão de jovens de uma região periférica do município de São Paulo acerca do processo empreendedor, de suas aspirações e temores e de sua disposição para abrir um negócio na região em que residem. Procedeu-se à revisão bibliográfica com vistas a conhecer o estado da arte da produção científica brasileira acerca do empreendedorismo juvenil. Foram, então, realizadas quinze entrevistas com universitários de Administração de uma universidade da região. Adotou-se como procedimento analítico básico a análise temática, em que, partindo-se de assertivas que expressavam a compreensão do problema sob a perspectiva dos próprios entrevistados, foram gerados temas, que, após sintetizados, possibilitaram uma teorização substantiva acerca do assunto. Constata-se que a associação entre empreendedorismo e sonho, coincidindo com a perspectiva da teoria visionária do empreendedorismo e que o local de residência constitui importante elemento na determinação do local desejado para empreender; o que indica adequação dos fundamentos das teorias relativas à identidade de lugar.

Palavras-chave: Empreendedorismo jovem. Estudantes universitários. Disposição para empreender. Identidade de lugar.

\section{ABSTRACT}

This research aims to explore the understanding of young people from a peripheral region of the city of São Paulo about the entrepreneurial process, their aspirations and fears and their willingness to open a business in the region in which they reside. $A$ bibliographical review was carried out in order to know the state of the art of Brazilian scientific production about youth entrepreneurship. Fifteen interviews were conducted with university students from a university in the region. It was adopted thematic analysis as basic analytical procedure, in which, based on assertions expressing the understanding of the problem from the perspective of the interviewees themselves, themes were generated, which, after being synthesized, made possible a substantive theorization about the subject. The association between entrepreneurship and dream coincides with the perspective of the visionary theory of entrepreneurship, and that the place of residence is an important element in determining the desired place to undertake, indicating adequacy of the foundations of theories related to the identity of place.

Keywords: Young entrepreneurship. College students. Willingness to undertake. Place identity. 


\section{INTRODUÇÃO}

O Brasil pode ser considerado um dos países mais empreendedores do mundo. Segundo o GEM (2012), a proporção dos brasileiros que deseja ter o próprio negócio $(43,5 \%)$ é superior à dos que desejam fazer carreira em empresas $(24,7 \%)$. Os dados fornecidos por esse instituto indicam, ainda, que $18,2 \%$ dos empreendedores iniciais situam-se na faixa entre 18 e 24 anos e o maior percentual desses empreendedores $(33,8 \%)$ concentra-se na faixa de 25 a 34 anos. Contudo, em que pese os elevados índices de empreendedorismo no país e de participação de jovens no processo empreendedor, constata-se uma lacuna nas pesquisas associadas relacionadas ao empreendedorismo juvenil.

Bem expressa essa lacuna o estudo divulgado recentemente por Bacelar e Teixeira (2016), que abrangeu levantamentos bibliográficos sobre empreendedorismo no Brasil, entre 2002 e 2014. Esses autores, mediante investigação nas bases de dados SPELL, EnANPAD e EGEPE, identificaram nesse período 25 revisões de literatura sobre empreendedorismo, que foram classificados segundo as categorias: social, sustentável, público, de gênero, hotelaria e feminino. Ou seja, não foram realizados levantamentos bibliográficos que enfatizassem o empreendedorismo juvenil. Visando atualizar esses dados, os autores desse trabalho também promoveram levantamento bibliográfico, abrangendo 444 trabalhos, que foram classificados em 16 categorias, dentre as quais, empreendedorismo feminino, empreendedorismo familiar e empreendedorismo étnico. Assim, constata-se a lacuna referente a empreendedorismo juvenil.

Não há como deixar de reconhecer a importância do empreendedorismo juvenil. Como a etapa da vida definida como juventude é aquela em que seus integrantes se preparam para a vida profissional, tornase necessário garantir que Ihes seja conferida capacitação para empreender. Para que esta capacitação ocorra de maneira adequada, torna-se necessário que esses jovens participem de programas de formação, treinamento e aperfeiçoamento. Isto porque educação constitui a resposta mais racional para aos reclamos de capacitação profissional.

Constata-se a existência de múltiplos projetos e ações voltadas à capacitação de jovens para empreender: incubadoras de empresas, associações de jovens, empresas juniores, programas de fomento ao empreendedorismo e até mesmo cursos específicos de empreendedorismo oferecidos por instituições de ensino superior. Menção especial merece a parceria estabelecida entre a Federação das Indústrias do Estado de São Paulo, o SEBRAE-SP, o SENAI e o Centro de Empreendedorismo e Novos Negócios da Fundação Getúlio Vargas, que elaboraram o Manual do Jovem Empreendedor e procuram auxiliar na capacitação empreendedora dos jovens brasileiros.

Mas, para que as ações voltadas ao empreendedorismo juvenil sejam eficazes, requer-se o conhecimento das características dessa população, bem como do contexto em que atuam. Assim, torna-se necessário saber o que leva os jovens a empreender, qual o setor em que pretendem atuar, qual a percepção que tem acerca de sua capacidade empreendedora, quais as suas aspirações e temores em relação ao empreendimento e o local em que pretendem empreender.

O local em que pretendem empreender assume significativa importância porque nos remete à questão das regiões empreendedoras. Considere-se, a propósito os estudos desenvolvidos por Julien (2010) acerca do desenvolvimento regional. Esse autor constatou que algumas regiões podem ser consideradas vitoriosas porque apresentam indiscutíveis vantagens, tais como, a proximidade de grandes centros e a abundância de 
recursos. Mas constatou, também, que há regiões que, embora não apresentando vantagens tão evidentes, apresentam elevado grau de desenvolvimento. Admite, então, que uma das razões que poderiam explicar a condição vitoriosa dessas regiões seria a presença significativa de empreendedores.

Assim, quando se pensa no potencial do empreendedorismo para o desenvolvimento de uma região, particular atenção deve ser conferida à disposição dos jovens para empreender no local. Interessa saber o quanto eles se identificam com a região em que moram e quão promissor acreditam que poderá ser o seu empreendimento no local, bem como os fatores que os impulsionam para empreender, o que implica a realização de pesquisas com rigor científico para compreender os fatores capazes de motivar esses jovens para empreender preferencialmente na região em que residem.

Numa grande região metropolitana - como é o caso da Região da Grande São Paulo - podem ser identificados muitos locais promissores para novos empreendimentos. Como, porém, um empreendimento em muitas dessas áreas geográficas exige grande disponibilidade de capital, para maioria dos jovens o investimento não se mostra viável, pelo menos em curto prazo. Assim, para muitos jovens que residem na periferia das grandes cidades, o local cogitado para sediar seu empreendimento tende a ser aquele em que residem.

A decisão para empreender num determinado local depende de muitos fatores, tais como: capital disponível para a abertura do negócio, percepção acerca da adequação do local, rede de contatos e identificação com o local. Daí a necessidade de pesquisas científicas voltadas tanto para descrever a disposição dos jovens para empreender no local em que residem como para verificar a existência de relação entre essa disposição e fatores de natureza socioeconômica e perceptiva.

Requer-se, portanto, a realização de pesquisas descritivas e explicativas que possam descrever com precisão as características dos empreendedores jovens bem como os fatores influenciadores da sua disposição para empreender em determinados locais. As revisões bibliográficas, notadamente a elaborada por Bacelar e Teixeira (2016), indicam que ainda é incipiente a produção científica nacional acerca do empreendedorismo jovem. Assim, o que se requer prioritariamente é a realização de pesquisas de caráter exploratório que possibilitem uma melhor formulação das questões de pesquisa, o estabelecimento de modelos teóricos adequados, bem como a formulação de hipóteses antecipadoras do comportamento empreendedor em contextos específicos. Daí a realização da presente pesquisa que tem como objetivo explorar a compreensão de jovens de uma região periférica da Grande São Paulo acerca do processo empreendedor, de suas aspirações e temores em relação a possíveis empreendimentos, bem como de sua disposição para empreender na região em que residem.

Trata-se, pois, de um estudo de caráter essencialmente exploratório, já que não tem como propósito fornecer respostas conclusivas, mas proporcionar nova compreensão do problema, bem como a formulação de hipóteses para a realização de estudos posteriores de caráter descritivo e explicativo. $O$ universo dessa pesquisa é, pois, constituído por universitários de Administração residentes na região constituída pelo bairro de São Miguel Paulista, no município de São Paulo.

A escolha dessa localidade deve-se ao fato de constituir importante região periférica da capital paulista. Por estar em uma das regiões de povoamento mais antigo e por se localizar distante do centro da cidade, São Miguel Paulista pode ser facilmente caracterizado do ponto de vista geográfico, histórico e cultural. A escolha de estudantes do curso de graduação em Administração, por sua vez, deve-se ao fato de 
ser este um dos cursos mais voltados ao empreendedorismo, já que até mesmo em muitos deles incluem-se disciplinas que tratam especificamente de empreendedorismo.

O relato desta pesquisa estrutura-se em cinco seções: 1) Introdução, que esclarece acerca do contexto atual no qual está inserida a pesquisa, o problema de pesquisa, os objetivos e a justificativa; 2) Revisão da Literatura, que fornece o referencial para a compreensão do tema em questão; 3) Método, que esclarece acerca dos procedimentos adotados na coleta e análise dos dados; 4) Análise e discussão dos dados; e 5) Considerações finais.

\section{REVISÃO DA LITERATURA}

A revisão da literatura neste trabalho corresponde à identificação de construções teóricas significativas para a compreensão do problema e de pesquisas empíricas realizadas no Brasil em relação a empreendedorismo juvenil, motivação para empreender e identidade de lugar e disposição para empreender.

\section{Empreendedorismo juvenil}

Em virtude da importância assumida do empreendedorismo, verifica-se a ampliação de pesquisas relativas aos mais diversos segmentos de empreendedores, tais como: empreendedorismo feminino, empreendedorismo indígena, empreendedorismo em comunidades rurais, empreendedorismo em comunidades de pescadores, empreendedorismo entre portadores de necessidades especiais, empreendedorismo homossexual, empreendedorismo entre afrodescendentes, empreendedorismo entre latino-americanos de segunda geração, dentre outros (NOVAES; GIL, 2009). Estudos sobre empreendedorismo jovem também vem se tornando frequentes, embora ainda em número bem menor que o de outros segmentos. Considere-se, por exemplo, que a partir do Encontro de Estudos Sobre Empreendedorismo e Gestão de Pequenas Empresas - EGEPE, o mais importante evento acadêmico sobre empreendedorismo realizado no Brasil, passou, a partir de 2008, a incluir uma área com o título Empreendedorismo Jovem. Nesse primeiro evento, no entanto, foi apresentado um único trabalho tratando de empreendedorismo juvenil.

Soares e Machado (2005) realizaram pesquisa com 16 empreendedores, integrantes de uma rede de jovens empresários em um município norte paranaense e concluíram que estes apresentam elevada formação escolar, têm acesso a informação, sua visão reflete o desejo de crescimento dos negócios e perspectivas de melhoria tecnológica, embora enfatizem a dificuldade de obter recursos financeiros.

Bulgacov et al. (2011) constataram que no Brasil a maioria dos jovens são autoempregadores, empregam poucas pessoas, têm pouca estrutura para enfrentamento de riscos e apresentam baixo índice de escolaridade: fatores que elevam a probabilidade do risco de fracasso do negócio. Constataram também que os empreendimentos que sobrevivem não resultam em impactos econômicos, manter de forma precária a sobrevivência de um grande número de jovens excluídos do mercado de trabalho formal. Jovens que empreendem por oportunidade formam um grupo relativamente pequeno. Concluindo, os autores destacam que o apoio e a sustentabilidade do jovem empreendedor dependem do contexto geral e de políticas educacionais. 
Motta e Trevisan (2003) realizaram pesquisa com membros da Associação de Jovens Empresários de Santa Maria, no Rio Grande do Sul, e verificaram que a maioria não descende de família de tradição empreendedora e que sua principal motivação foi a abertura do próprio negócio. Constataram também, que esses empreendedores conseguiram superar as expectativas de sobrevivência das empresas, superando em média de três anos de vida as pequenas empresas.

Santos, Minuzzi e Cruz (2010) investigaram o potencial e a propensão empreendedora de alunos do Curso de Farmácia da Universidade Federal de Alagoas e concluíram que: 1) os jovens possuem forte potencial empreendedor, 2) que em relação a essa característica não existem diferenças de gênero, 3) que sua intenção de empreender não decorre de ter pai empreendedor, e 4) que existe maior influência para eles empreenderem por parte dos pais que são empreendedores, quando comparados com pais não empreendedores.

\section{Motivação para empreender}

A motivação para empreender - como qualquer outra motivação - tem origem numa necessidade (MASLOW, 1954). Mas, o sucesso do empreendimento depende também das características pessoais. Assim, Timmons (1994), num trabalho que considerou mais de 50 estudos sobre empreendedorismo, definiu as características mais consensuais dos empreendedores: 1) comprometimento e determinação; 2) liderança; 3) obsessão pela oportunidade; 4) tolerância ao risco, ambiguidade e incerteza; 5) criatividade, autoconfiança e capacidade de adaptação; e 6) motivação para sobressair.

Para Filion que criou a Teoria Visionária do Empreendedorismo, o empreendedor é uma pessoa que imagina e desenvolve visões (FILION, 1993; FILION; DOLABELA, 2000). Estas visões podem ser de três tipos: visão emergente (ideia de produto ou serviço que pretende lançar), visão central (resultado de uma ou mais visões emergentes) e visão complementar (atividade de gestão definida para sustentar a realização da visão central). Para dar suporte às formações da visão é preciso que o empreendedor tenha: conceito de si, energia, liderança, compreensão de um setor e relações.

Para Dornelas (2011), o empreendedor precisa ser visionário, saber tomar decisões, saber explorar ao máximo as oportunidades, ser determinado e dinâmico, ser otimista e apaixonado pela atividade que exerce, ser independente, ser líder e formador de equipe, ser bem relacionado, ser organizado, ser planejador, possuir conhecimento e assumir riscos calculados. São essas as características que definem o empreendedor "de sangue", que é muito diferente do empreendedor por necessidade, que parece ser o mais frequente nos tempos atuais. Mas é necessário considerar que, além das características pessoais, deve-se levar em consideração aspectos socioeconômicos capazes de influenciar a disposição para empreender. Como indica o estudo realizado por Bianchi (1993), que ao analisar o empreendedorismo nos Estados Unidos, constatou que o sucesso dos empreendedores tem a ver também com as características: 1) ser filho de pais que desenvolveram atividades profissionais autônomas; 2) ter sido despedido de mais de um emprego; 3) ser imigrante ou filho de imigrantes; 4) ter trabalhado anteriormente em empresa com mais de 100 empregados; 5) ser o filho mais velho; e 6) ter formação universitária. 
Miao e Liu (2010) realizaram pesquisa com 327 empresários, e seus resultados indicaram que fatores psicológicos do indivíduo (estado de alerta empresarial e conhecimento prévio) têm papel fundamental no reconhecimento da oportunidade empresarial e influenciam na tomada de decisão. Assim, concluíram que o conhecimento prévio antecede o reconhecimento de oportunidades e impacta diretamente na tomada de decisões.

Pesquisa realizada por Mello, Leão e Paiva Júnior (2006), associou o processo de reconhecimento de oportunidade aos seus interesses profissionais. Outro aspecto sinalizado pelos autores é o de empreendedores estarem atentos aos nichos de mercados não atendidos e de necessitarem levantar informações sobre o mesmo, além de buscarem conhecimentos relacionados aos esforços de marketing.

De acordo com Knuson et al. (2004), a intenção de iniciar e manter o comportamento empreendedor sofre a influência de vários fatores, tais como: características individuais, ambiente social, ambiente de negócios, metas pessoais e ideia de um negócio viável. Ainda, segundo esses autores, a percepção e orientação para metas estão relacionadas à motivação para empreender.

Pesquisa realizada por Bernardi (2003) indica dez razões que levam as pessoas a se motivarem na abertura de novos negócios: necessidade de realização, implementação de ideias, desejo de independência, fuga da rotina profissional, maior responsabilidade e riscos, prova de capacidade, maior ganho, status e controle sobre a qualidade de vida.

Os resultados de pesquisa realizada por Machado et al. (2003) com 90 empreendedoras de três países, dentre eles o Brasil, indicam que a principal razão que as levou a abrir um negócio foi à realização pessoal $(30 \%)$, seguida de percepção de oportunidade de mercado $(26,66 \%)$. Os motivos envolvendo problemas no trabalho anterior, falta de perspectiva na carreira e perda de emprego, corresponderam a $21,11 \%$. Razões ligadas a questões familiares, perda do marido, querer encontrar uma ocupação para a família, querer comprar a empresa do pai ou a empresa em que trabalhava, abertura de filial dos negócios da família e incentivo por parte dos familiares responderam por $17,78 \%$ dos casos. As autoras sugerem que para as empresas criadas mais recentemente, a falta de emprego ou de perspectiva na carreira podem ter uma significação maior.

Vicenzi (2011) analisou os fatores motivadores do empreendedorismo que influenciaram nas decisões de conteúdo estratégico em empresas da cidade de Foz do Iguaçu (PR). Nesse estudo, as características dos empreendedores que mais se destacaram foram: determinação, vontade/motivação e coragem/ousadia. Os principais fatores que influenciaram na escolha de produtos/serviços foram: conhecimento teórico/formação, experiência prévia no ramo e sociedade com pessoas mais experientes. Por fim, os motivadores da decisão para abrir um negócio foram: oportunidade no mercado, realização profissional e o desejo de independência.

Em estudo desenvolvido por Guedes (2009), fatores intrínsecos, como o desejo de realização, vontade de aplicar os próprios conhecimentos e vontade de satisfação pessoal com o próprio trabalho mostraram-se mais fortes para motivação dos empreendedores do que os fatores extrínsecos, como reconhecimento pelas pessoas e retorno financeiro.

Barros, Fiúsa e Ipiranga (2005) estudaram a trajetória de vida de três empreendedores e constataram que no primeiro caso a oportunidade e a necessidade foram determinantes para a abertura do negócio, visto que a empreendedora não tinha nenhuma perspectiva de trabalho na época em que abriu a empresa. Assim, 
o sucesso do negócio estaria relacionado à sua criatividade e ao conhecimento sobre o produto e o mercado. No segundo caso, o negócio iniciou-se com uma dona de casa que buscava complementar a renda da família e ocupar mais o seu tempo. Posteriormente, o negócio passou a ser dirigido pelo filho que impulsionou o crescimento e a consolidação dos negócios no mercado. No terceiro caso, a família influenciou na origem do negócio, que surgiu a partir da oportunidade percebida no mercado, conhecimento do negócio e experiência prévia.

Jonathan e Silva (2007) realizaram uma pesquisa com 49 empreendedoras cariocas de diversos setores da economia e constataram que a trajetória delas foi marcada pela busca da autorrealização e também que no exercício do empreendedorismo elas sentiam satisfação, dedicavam-se com afinco e estavam profundamente comprometidas com seu negócio.

\section{Identidade de lugar e disposição para empreender}

O conceito de identidade de lugar refere-se à importância simbólica de um lugar como repositório de emoções e relacionamentos que conferem significado e propósito para a vida das pessoas (WILLIAMS; ROGGENBUCK, 1990; SHAMAI, 1991; GIULIANI; FELDMAN 1993). Graças às suas atitudes, sentimentos, ideias, memórias, valores e preferências pessoais é que elas se tornam capazes de compreender o ambiente em que vivem e sua experiência global. Como essas pessoas interagem com diversos lugares e espaços, tornam-se capazes de avaliar as propriedades em diferentes ambientes e satisfazer suas diversas necessidades. E como elas vivem e criam memórias dentro de um lugar, tendem a desenvolver apego por ele e mediante uma conexão pessoal com esse lugar, obtêm sentimento de pertença e de finalidade que confere significado e sentido às suas vidas (TUAN, 1980; RELPH, 1976; BUTTIMER, 1980).

Basílio, Gil e Oliveira (2012) realizaram um survey com 423 estudantes de três instituições de ensino superior localizadas na Zona Leste do Município de São Paulo (SP). A maioria dos estudantes indicou maior disposição para empreender no próprio bairro em que moram. O survey também mostrou a existência de correlação positiva entre a preferência por trabalhar por contra própria e a disposição para empreender no próprio bairro em que moram. Não indicou, no entanto, relação significativa entre o nível de identificação com o bairro e a disposição para empreender nessa localidade. Concluiu, por fim, que os estudantes têm maior disposição para empreender no local em que residem em virtude do conhecimento que já tem desse local, ou do temor em abrir seu negócio em local menos conhecido.

\section{MÉTODO}

O presente estudo pode ser definido como exploratório, já que, conforme a clássica definição proposta por Selltiz et al. (1972), tem como objetivo ampliar o conhecimento dos pesquisadores acerca de determinado fenômeno com vistas à sua investigação de forma mais estruturada. Com efeito, o que se pretende é uma melhor compreensão do problema mediante imersão na literatura pertinente e contato com atores relevantes para obtenção de uma melhor compreensão do problema, bem como a formulação de hipóteses orientadoras para futuro estudo. 
Assim, procedeu-se a revisão da literatura relativa ao tema, com foco na produção científica realizada no Brasil. Procedeu-se, para tanto, à identificação de artigos publicados em periódicos nacionais da área de Administração, teses e dissertações, bem como relatos apresentados em eventos como os promovidos pela Associação Nacional de Pós-Graduação em Economia e Contabilidade - ANPAD e pela Associação Nacional de Estudos em Empreendedorismo e Gestão de Pequenas Empresas - ANEGEPE. Os principais resultados desta revisão são indicados na seção Revisão da Literatura.

Sequencialmente, procedeu-se à realização de um survey exploratório (ZIKMUND, 2013), baseado na aplicação de entrevistas focalizadas com 15 estudantes de Administração de uma universidade localizada na região de São Miguel Paulista. A seleção dos estudantes deu-se pelo critério da intencionalidade, já que teve como propósito obtenção de depoimentos de estudantes desse curso que fossem moradores do bairro e adjacências. Dado o caráter exploratório da pesquisa, as entrevistas assumiram um caráter informal. Assim, para sua realização, os pesquisadores, após o rapport, passaram à apresentação de questões genéricas referentes ao significado de empreendedorismo e à disposição para empreender. Aos entrevistados foi dada ampla liberdade para responder, ficando a participação dos pesquisadores restrita à solicitação de esclarecimentos e à retomada do foco da entrevista.

A análise das entrevistas foi feita mediante a utilização da estratégia da análise temática indutiva (GUEST; McQUEEN; NAMEY; 2012), que se desenvolve segundo as etapas: 1) familiarização com os dados; 2) geração dos códigos iniciais; 3) identificação de temas potenciais; 4) revisão e refinamento dos temas; 5) definição e nomeação dos temas; 6) busca de significados; e 7) elaboração de uma síntese.

\section{ANÁLISE E DISCUSSÃO DOS RESULTADOS}

Com base nos procedimentos preconizados para a realização de análise temática indutiva, foram analisados os dados obtidos mediante entrevistas. Assim, os temas identificados foram organizados em cinco categorias: 1) Significados de empreendedorismo; 2) Requisitos para empreender; 3) Área escolhida pra empreender; 4) Dificuldades percebidas para empreender; e 5) Identificação com a região. Procede-se, então, à análise e discussão desses resultados. 


\section{Significados de empreendedorismo}

Os estudantes definem empreendedorismo de diversas maneiras. Dentre as expressões utilizadas para esclarecer seu significado, estão: "realização de sonho", "estabilidade", "realização pessoal e profissional" e "forma de conseguir ter riqueza acreditando nas ideias que surgem". Constata-se íntima relação entre empreendedorismo e sonho. Tanto é que em cursos e palestras sobre empreendedorismo, voltados para jovens, com frequência sugerem leituras com títulos sugestivos como: Você é do tamanho dos seus sonhos (SOUZA, 2003) Nunca desista de seus sonhos (CURY, 2004) e Manual para sonhadores (TRUTMAN, 2013). Assim, foram obtidas declarações de estudantes, tais como:

Para empreender, primeiramente precisa de sonho, precisa ter vontade de fazer alguma coisa, a vontade eu acho que é o fator principal e depois vem o restante, vem os recursos financeiros, vem o apoio (Entrevistado 1).

Empreender é abrir um negócio um sonho que você tem. Abrir um negócio só pra você mesmo e de uma maneira que você goste. (Entrevistado 4).

Ser empreendedor é arriscar, é você ter um sonho, é você ter uma ideia e você correr atrás. (Entrevistado 9).

Acho que empreender é inovação, você conseguir buscar um algo. Acho que é sonho de todo brasileiro, ter um negócio próprio, ganhar muito dinheiro. (Entrevistado 15).

Esses depoimentos mostram consonância com a Teoria Visionária de Filion (1991), segundo a qual as pessoas motivadas para empreender vão criando, ao longo do tempo, ideias de produtos baseadas em sua experiência. Essas ideias emergem em estado bruto, refletindo, a princípio, apenas um sonho ou uma vontade ainda não muito bem definida. Nem todos os estudantes, no entanto, veem o empreendedorismo como a forma de realização de um sonho. O empreendedorismo também aparece como forma de estabilidade e realização, tanto profissional quanto pessoal:

Empreender é estabilidade, estabilidade de realização, tanto pessoal quanto profissional. (Entrevistado 11).

O empreendedorismo também é reconhecido como chance de ganhar mais do que se ganha como empregado, como a melhor forma de conseguir alcançar o sucesso financeiro e como o meio mais adequado para alcançar a condição de trabalhar por algo mais do que a simples sobrevivência. As falas de alguns estudantes chegam a colocar o empreendedorismo como uma grande chance para alcançar a riqueza. Ou seja, como forma de realizar sonhos:

Empreendedorismo é a principal forma de a pessoa ficar rica hoje em dia. Ou você nasce rico ou você tem uma ideia e investe nessa ideia. (Entrevistado 12). 
Os depoimentos dos estudantes expressam o caráter multifacetado do conceito de empreendedorismo. O que significa que para seu entendimento é preciso considerar muito mais do que as tradicionais concepções de empreendedorismo: por necessidade e por oportunidade. Mesmo porque, dentre os depoimentos, há os que enfatizam o seu aspecto social:

Empreendedorismo pra mim é cada dia você aprender mais e usar esse conhecimento para ajudar as pessoas. (Entrevistado 13).

\section{Requisitos para empreender}

A literatura sobre empreendedorismo indica que são muitos os requisitos para empreender. Os trabalhos mais difundidos (TIMMONS, 1994; SEBRAE, 2004; DORNELAS, 2011) enfatizam os requisitos pessoais, pois são os mais considerados nas ações voltadas à capacitação de empreendedores. Mas, não há como deixar de reconhecer a importância de fatores socioeconômicos nesse processo. Os depoimentos dos estudantes refletem essa multiplicidade de fatores. Assim, os requisitos com maior frequência são: "conhecimento", "coragem", "vontade", "qualidade", "ideia", "investimento" "relacionamento", "persistência" e "sonho".

O conhecimento é um dos requisitos mais lembrados pelos estudantes. Tanto no que se refere ao conhecimento do ramo que pretendem atuar quanto ao conhecimento acerca do que será preciso para iniciar o empreendimento. Em alguns casos o conhecimento aparece como elemento primordial. Como segue na seguinte declaração:

Você tem que ter conhecimento de tudo que você vai precisar, para depois você chegar e falar: eu já sei tudo o que eu preciso e tudo o que eu tenho que conseguir, todo tipo de informação possível para você poder empreender. (Entrevistado 11).

Embora o conhecimento seja reconhecido como elemento importante para garantir o sucesso do empreendimento, a maioria dos estudantes enfatiza que são muitos os requisitos pessoais necessários para empreender. Alguns depoimentos, como os que se seguem, indicam múltiplos requisitos, sem definir quais seriam os primordiais:

Exige bastante coisa, tem que ter o espírito empreendedor, tem que ter o conhecimento na área que você quer atuar, não ter medo, ter ali aquela persistência, porque de repente, no começo não dá certo, mas depois você vai encaixando ali, arrumando aqui e vai dando certo. (Entrevistado 4).

Eu acho que tem que ter força de vontade, tem que querer, tem que correr atrás, tem sempre que se comunicar, verificar e sempre estar atento, sempre estar lendo, pra verificar se acha alguma ideia, se surge alguma ideia, e também tem que ter um pouco de experiência, que é o que a gente aprende. (Entrevistado 5). 
O sonho - que foi apresentado por muitos estudantes como sinônimo de empreendedorismo também é identificado como elemento determinante do processo empreendedor. Embora aqui a concepção de sonho se confunda com a de vontade:

Para empreender primeiramente precisa de sonho, precisa ter vontade de fazer alguma coisa, a vontade eu acho que é o fator principal e depois vem o restante, vem os recursos financeiros, vem o apoio. (Entrevistado 1).

Mas, há estudantes que não associam o sonho à vontade de empreender. Como um estudante, que, embora reconhecendo a importância do sonho, reconhece que este pouco valor pode ter se não houver disposição para trabalhar:

Basta a pessoa não ter medo, ter vontade de trabalhar, porque o empreendedor não é só você sonhar, sonhar é fácil, mas você realizar é difícil e pra você realizar você tem que ter vontade de trabalhar. (Entrevistado 13).

Planejamento e pesquisa também são itens valorizados pelos estudantes. O que pode significar o reconhecimento da importância dos requisitos para empreender presentes no conteúdo dos programas de capacitação de empreendedores:

Acho que primeiro a pessoa tem que ter objetivo. Eu quero abrir uma empresa, uma loja de roupa, então o que você precisa pra fazer isso? Você precisa estudar o quê? O que você precisa buscar? Eu acho que é assim. (Entrevistado 15).

Tem que fazer uma pesquisa enorme para empreender porque senão pode falir a empresa facilmente, então tem bastante risco e precisa pesquisar bem. (Entrevistado 6).

É importante você fazer pesquisa, você buscar e observar o que o mercado está precisando e você investir e tentar dar o seu melhor. (Entrevistado 7).

Você tem que ter conhecimento de tudo que você vai precisar, para depois você chegar e falar: eu já sei tudo o que eu preciso e tudo o que eu tenho que conseguir, todo tipo de informação possível para você poder empreender e para você chegar ao valor que você vai utilizar. (Entrevistado 11).

A qualidade também é reconhecida como requisito importante para empreender. Trata-se, na opinião dos estudantes, de elemento importante para conquistar o mercado em que irão atuar e até mesmo como a principal responsável para se manter um empreendimento:

Acho que hoje pra você ganhar um mercado de qualquer setor, você precisa ter qualidade. Se você não tiver qualidade, você abre um negócio hoje e pode ter certeza que em um mês ou dois meses ele não vai pra frente. (Entrevistado 2) 
Disponibilidade financeira é reconhecida como requisito essencial. Mas ao tratar desse aspecto, os estudantes tendem a relativizar seu valor, justificando que outros requisitos devem aparecer conjuntamente para que o negócio tenha sucesso. Raramente o fator financeiro aparece nos discursos como o fundamental:

Primeiro uma ideia boa, tem que ter investimento, você só ganha dinheiro se você tiver dinheiro, você tem que investir. (Entrevistado 12).

A parte financeira é a principal, iniciar com um bom financeiro, mas vai mais da habilidade mesmo, porque tem muita gente que abre empresa, mas nem sabe o que está abrindo, como funciona e como lucrar, então acaba se perdendo, não adianta ter muito dinheiro e não saber levar o negócio adiante. (Entrevistado 8).

\section{Área escolhida para empreender}

A área escolhida é considerada pelos estudantes um fator relevante para a tomada de decisão para empreender. Há os que se decidem pela própria área em que já atuam. Mas, há os que, ao expressar essa escolha, falam de: "incerteza em relação à área em que atua", "interesse pela área de Administração" e "interesse por outras áreas".

De fato, a experiência na área em que já atuam pode ser valiosa, seja pelo conhecimento obtido ou pela experiência conquistada. Para alguns estudantes, o ramo de atividade em que atuam também pode despertar a preferência pela área escolhida. Assim, a abertura de um negócio que dê continuidade ao que já fazem é apresentada como sonho de alguns estudantes:

Meu sonho é abrir meu próprio negócio, se possível, na área do comércio de alimentos que é o ramo que eu já estou no meio já tem cinco anos. (Entrevistado 1).

Empreendedorismo é sonho. Eu tenho um sonho de empreender na área da consultoria, na parte de consultoria por conta do que eu vejo hoje em dia, da vivência que eu tenho em relação a parte de legislação, a parte tributária. Então eu me vejo empreendendo nessa área de consultoria, eu me vejo um empreendedor lá na frente. (Entrevistado 9).

Como são estudantes de Administração - que é a área mais vinculada ao processo empreendedor é natural que em sua maioria indiquem sua preferência por continuar atuando nessa área:

Eu iniciei cedo, desde o ensino fundamental eu já sabia que eu queria ir pra área de Administração. (Entrevistado 14).

Eu estudo Administração porque eu sou apaixonado por aquilo que eu faço, então tanto no âmbito profissional, quanto no estudantil eu sou cem por cento realizado, de saber que eu estou no caminho certo (Entrevistado 1) 
Nem todos os estudantes, no entanto, indicam certeza acerca da adequação de sua decisão. Assim, a incerteza de estar atuando em uma área que não seja a preferida pode ser elemento importante para a escolha de outra área. Porém, a incerteza em relação à área, por si só, não conduz à disposição de deixar o emprego e partir para o empreendedorismo. Pôde ser percebido que a solução para a busca de uma área preferida pode estar na mesma empresa em que o estudante atua:

A empresa é grande e eu tenho como crescer em outros departamentos, então eu estou buscando outra área, informações gerenciais, compras, eu quero uma coisa mais dinâmica. A Contabilidade, eu acho que é muito fechada, é muito monótona, assim eu trabalho todo dia a mesma coisa, igualzinho, igualzinho, igualzinho, não é o que eu quero pra mim. Eu quero uma coisa mais dinâmica, trabalhar com compras, é bem bacana o compras lá, bem legal. (Entrevistado 15).

Também foram identificadas manifestações de interesse por outras áreas. Nesses casos, a razão indicada está relacionada ao fato de gostarem mais da outra área e não de possíveis vantagens que esta objetivamente possa oferecer:

A minha pós-graduação eu estou pensando em fazer pra área social porque eu gosto muito dessa área. Tanto pessoa quanto animal, porque eu sou apaixonada por animais. Hoje o meu trabalho está mais voltado para essa área social. Lá na Sabesp, eu pedi essa opção. Eu trabalho com a tarifa social que é um benefício do governo no qual eu consigo baixar muitas contas, reformar conta, principalmente em favela; então o nosso foco hoje é esse, o meu foco é pessoa. (Entrevistado 14).

$\mathrm{Na}$ empresa em que eu trabalho eles trabalham com logística de informação, mas na verdade o que eu descobri é que eu não vou para nenhuma dessas áreas. Nem vendas, nem TI, nem nada, eu gosto mesmo é de Psicologia. (Entrevistado11).

\section{Dificuldades percebidas para empreender}

Os estudantes também identificam dificuldades para empreender. As barreiras mais consideradas são: "impostos e carga tributária", "falta de recursos financeiros" e "dificuldade para a obtenção de recursos" e "concorrência". A dificuldade mais presente é referente a recursos financeiros. Tanto pelo fato de não possuir os recursos necessários quanto pelas barreiras encontradas para obtê-los:

A dificuldade hoje seria o financeiro, porque querendo ou não, você pode ter uma ideia, mas pra colocar em prática você tem que ter o financeiro. (Entrevistado 6).

A dificuldade pra eu abrir um empreendimento seria o financeiro, teria que ter uma reserva, algo pra começar, por enquanto não dá (Entrevistado 4).

Eu acho que o grande " $X$ " de todo empreendedor e de toda empresa na verdade é o dinheiro. Se você corre atrás de um banco, você tem um juro gigante pra pagar, se você corre atrás de um familiar, você pode correr o risco de não ter. E pra você correr atrás de um investidor, de alguém que realmente irá investir no seu negócio, aí você tem que ter uma estrutura, uma ideia bem formada, uma estrutura bem elaborada. (Entrevistado 9). 
Mas, eu ainda acho que com vinte anos é muito difícil um banco ou até mesmo o próprio BNDS chegar e falar assim: vou dar 100 mil reais na mão de um "cara" de vinte anos. (Entrevistado 1).

As dificuldades de ordem financeiras estão presentes em pesquisas com jovens empreendedores. Como a realizada por Soares e Machado (2005) com 16 jovens empresários que, embora com elevada formação escolar e acesso a informação, enfatizavam a dificuldade para obter recursos financeiros. Justificase essa ênfase, pois os recursos, juntamente com a oportunidade e a equipe constituem os três aspectos críticos do processo empreendedor (TIMMONS, 1994). Mas cabe ressaltar que, a análise dos recursos necessários para o início do negócio deve ser a última a ser feita, para evitar que o empreendedor restrinja a análise da oportunidade, que deve ser a primeira das tarefas a ser realizada (DORNELAS, 2011).

Intimamente relacionada ao fator financeiro, a questão referente à carga tributária também é lembrada pelos estudantes:

Para muitos jovens é por causa do dinheiro. Mas, é que quando vai empreender e só pensa no dinheiro, a pessoa já faz errado. Ela acha que só precisa do dinheiro e esquece que tem muitos problemas de impostos, a pessoa tem que saber qual é o setor que realmente trabalha e os impostos que o envolvem. (Entrevistado 10).

A maior dificuldade no Brasil é a carga tributária. Eu acho que é o que pesa mais. A pessoa pensa em abrir um negócio, mas, começa a pensar, será que vale a pena? Muita gente não abre firma, não constitui mesmo uma empresa e fica trabalhando ilegal, abre uma loja física só que não tem registro na Junta Comercial, não tem nada. (Entrevistado 15).

A carga tributária constitui dificuldade das mais expressivas para quem pretende empreender. Principalmente porque o desejo de se estabelecer formalmente é muito forte. Mas, na prática, a carga tributária corresponde à grande diferença entre ser formal e informal. Mesmo com as inovações trazidas pela Lei Complementar № 128, de 19/12/2008, que criou condições únicas para o trabalhador informal, possibilitando que seja um Empreendedor Individual devidamente legalizado, desonerando-o de diversas taxações impostas aos empresários de maior porte.

A busca pelo sucesso e pelo dinheiro faz com que a concorrência também seja vista como dificuldade para empreender:

A dificuldade é a concorrência, vai ter uma concorrência muito grande no mercado, são vários jovens que querem a mesma coisa: sucesso, dinheiro, então vai ter concorrência, vai ser difícil, mas o "bom" vai conseguir. (Entrevistado 13)

\section{Identificação com a região}

O trabalho por conta própria e a capacidade de gerar o próprio negócio são reconhecidos como importantes elementos do processo empreendedor, não apenas quando se trata de temas como inclusão e desenvolvimento pessoal, mas também, quando se busca o desenvolvimento econômico e social de regiões e mesmo de países. Por essa razão é que ações em prol do empreendedorismo são reconhecidas como fundamentais para as regiões que buscam se tornar vitoriosas (JULIEN, 2010). Daí a importância conferida 
na presente investigação à questão relacionada à identificação do jovem empreendedor com a região em que moram.

O local de residência constitui importante elemento na determinação do local desejado para empreender. Conforme indicam as teorias relativas à identidade de lugar, as pessoas vivem e criam memórias dentro da localidade, avaliam o ambiente em que vivem, interagem com seus elementos, tendem a desenvolver apego por ele e, por meio dessa identificação, definir propósitos para suas vidas (TUAN, 1980; BUTTIMER, 1980; RELPH, 1976). O que poderia explicar o fato de alguns estudantes, ao falarem acerca do local em que pretendem empreender, simplesmente indicarem a região em que moram, sem maiores considerações:

Eu moro em São Miguel e se eu fosse abrir um empreendimento seria em São Miguel mesmo. (Entrevistado 6).

Eu moro na Curuçá em São Miguel Paulista e eu abriria um sex shop na minha própria região. (Entrevistado 14).

Mas a percepção acerca do futuro promissor da região também é um fator que desperta o interesse para empreender no local em que residem:

A Zona Leste está em crescimento, está em expansão. Itaquera, a nossa região de Itaquera com estádio ao redor, vai ter que abrir muitos empreendimentos, prédios, condomínios. Eu acho uma área bacana de investir, aquela parte de Itaquera está crescendo muito, seria legal abrir hoje uma loja. (Entrevistado 15).

Eu moro na região leste, no bairro de São Miguel. Eu penso em empreender aqui na região leste porque eu vejo que é um mercado que está em crescimento. (Entrevistado 9).

Eu moro aqui perto em São Miguel, na Vila Pedro Nunes. Abriria meu negócio na Zona Leste porque essa classe está em ascensão. (Entrevistado 12).

A identificação de necessidades da região também constitui elemento importante na determinação do interesse em empreender na própria região:

Às vezes eu procuro algo na região em que moro e não acho. Então eu fico querendo dar isso para as pessoas e pelas minhas amigas que às vezes falam: nossa eu fui comprar tal coisa e não achei, não tem, não tem. (Entrevistado 4).

Empreendedorismo eu acho uma coisa extremamente importante, eu acho que hoje o empreendedor é acima de tudo o "cara" que monta a empresa, ele é que vai abrir janela e vai abrir mais portas de empregos para a sociedade, é quem vai gerar uma renda na região onde ele está e mesmo com todos os contrapontos de governos e tudo mais o empreendedorismo hoje é extremamente importante. (Entrevistado 9). 
Alguns estudantes manifestaram interesse em empreender não no próprio bairro, mas em outros um pouco mais distantes, embora pertencentes à macrorregião da Zona Leste. A justificativa dessa preferência estaria não apenas na estrutura fornecida por esses bairros, mas também na segurança, como indicam alguns depoimentos:

Se eu fosse abrir um negócio eu acho que seria no Tatuapé. Mesmo a concorrência sendo grande, porque a concorrência no Tatuapé é grande, mas eu acho que iria dar certo. (Entrevistado 11).

O problema é a insegurança de abrir um posto de gasolina aqui na Zona Leste. Você abre e depois vem alguém e vandaliza ou quebra qualquer coisa. Pois, tem gente aqui que respeita, mas tem gente que vandaliza esse é o problema. (Entrevistado 10).

Como eu pretendo abrir uma consultoria executiva, não pode ser em bairros que não possuam empresas capacitadas pra contratar esses profissionais. Então na Zona Leste, poderia ser Mooca ou Anália Franco, que é o mínimo. Isso iniciando e pensando muito baixo. (Entrevistado 3).

\section{CONSIDERAÇÕES FINAIS}

Os resultados indicam uma forte associação entre empreendedorismo e sonho, corroborando a perspectiva da teoria visionária do empreendedorismo. Outros fatores associados ao empreendedorismo são: estabilidade, realização profissional e chance de alcançar sucesso e riqueza.

O conhecimento, tanto em relação ao ramo que pretendem atuar quanto ao conhecimento acerca do que será preciso para iniciar o empreendimento são os fatores mais presentes nos depoimentos dos estudantes no que se refere aos requisitos para empreender. Os estudantes também valorizam a vontade de empreender, os contatos pessoais, a disponibilidade financeira e o planejamento do negócio. Os estudantes identificam como principais dificuldades para empreender: impostos e carga tributária, falta de recursos financeiros, dificuldade para a obtenção de recursos e concorrência.

A área escolhida é considerada pelos estudantes fator relevante para a tomada de decisão para empreender. É recorrente a indicação de interesse por empreender na própria área em que já atuam. Também foram identificadas manifestações de interesse por outras áreas, mas as razões indicadas relacionam-se mais ao fato de gostarem mais da outra área do que a possíveis vantagens que esta objetivamente possa oferecer.

O local de residência constitui importante elemento na determinação do local desejado para empreender. $\mathrm{O}$ que contribui para corroborar princípios das teorias relativas à identidade de lugar. Essas teorias indicam que as pessoas vivem e criam memórias dentro da localidade, avaliam o ambiente em que vivem, interagem com seus elementos, tendem a desenvolver apego por ele e, por meio dessa identificação, definir propósitos para suas vidas. Assim, os resultados obtidos indicam a conveniência de se considerar a identificação com a região como significativa nos estudos sobre empreendedorismo jovem. Uma consequência prática destes achados poderia ser, por exemplo, a de propor às entidades empenhadas na promoção do empreendedorismo que incentivem a identificação dos jovens com a região em que residem. Identificação esta que deve se dar não apenas em termos reconhecimento da região, mas de vinculação 
afetiva e de disposição para atuar em prol de seu desenvolvimento, para que possam se tornar regiões empreendedoras.

Há que se considerar que o presente estudo tem um caráter exploratório. Visa proporcionar uma nova compreensão acerca do significado que os estudantes universitários da Região de São Miguel Paulista atribuem ao processo empreendedor, de suas aspirações e temores em relação a possíveis empreendimentos, bem como acerca de sua disposição para empreender na região em que residem. Distingue-se, porém, dos estudos exploratórios clássicos por adotar como estratégia analítica básica a análise temática. Assim, partindo-se de assertivas que expressavam a compreensão do fenômeno empreendedor sob a perspectiva dos próprios entrevistados, foram definidos e refinados temas, os quais possibilitaram a obtenção de uma síntese que pode contribuir para a construção de uma teoria substantiva acerca da disposição de jovens para empreender na região em que residem. Recomenda-se, portanto, a realização de outros estudos que enfatizem o papel da identidade de lugar no processo empreendedor. Os resultados desses estudos poderão, então, ser considerados como blocos para a construção de uma teoria de mais amplo alcance acerca do processo empreendedor.

\section{REFERÊNCIAS}

BACELAR S. D.; TEIXEIRA, R. M. Produção Científica sobre Empreendedorismo no Brasil: estudo bibliométrico das publicações em periódicos e eventos entre 2008 e 2014. IX EGEPE, Passo Fundo, RS. Anais... Passo Fundo, 2016.

BARROS. F. S. O; FIÚSA, J. L. A.; IPIRANGA, A. S. R. O. Empreendedorismo como estratégia Emergente de Gestão: histórias de sucesso. O\&S, v. 12, n. 33, abr/jun, 2005.

BASILIO, M. D.; GIL, A. C.; OLIVEIRA, P. B. Identidade de lugar e disposição para empreender. Pretexto. Belo Horizonte, v. 13, n. 4, p. 123-136, out/dez, 2012.

BERNARDI, L. A. Manual de Empreendedorismo e Gestão. São Paulo: Atlas, 2003.

BIANCHI, A. Who's most likely to go it alone? Inc. v. 15, n. 5, 1993.

BULGACOV, Y. L. M.; CUNHA, S. K. CAMARGO, D.; MEZA, M. L. BULGACOV, S. Jovens empreendedores no Brasil: a busca do espaço da realização ou a fuga da exclusão? RAP. Rio de Janeiro, v. 45, n. 3, p. 695-720, maio/jun, 2011.

BUTTIMER, A. Social space and the planning of residencial areas. In: BUTTIMER, A.; SEAMON, D. (Orgs.). The human experience of space and place.London: Croom Helm. p. 21-54, 1980.

CURY, A. Nunca desista de seus sonhos. Rio de Janeiro: GMT Editores, 2004.

DORNELAS, J. C. A. Empreendedorismo: transformando Ideias em negócios. 4 ed. Rio de Janeiro: Elsevier/Campus, 2011.

FILION, L. J. Visão e relações: elementos para um metamodelo empreendedor. Revista de Administração de Empresas, v.33, n. 6, p. 50-61, nov/dez. 1993.

FILION, L. J.; DOLABELA, F. Boa ideia! E Agora? Plano de negócio, o caminho seguro para criar e gerenciar sua empresa. São Paulo: Editora de Cultura, 2000.

GIULIANI, M.V., FELDMAN, R. Place attachment in a developmental and cultural context. Journal of Environmental Psychology, n. 13, p. 267-274, 1993.

GLOBAL ENTREPRENEURSHIP MONITOR - GEM.Empreendedorismo no Brasil - Relatório Executivo, 2012. GEM, 2012.

GUEDES, S. A. A carreira do Empreendedor. Dissertação de Mestrado em Administração. Programa de pós-graduação em Administração da USP, São Paulo160 p. 2009.

GUEST, G.; McQUEEN, K.M,; NAMEY, E.E. Applied thematic analysis. Thousand Oaks, CA: Sage Publications, 2012.

JONATHAN, E. G.; SILVA, T. M. R. Empreendedorismo Feminino: Tecendo a Trama de Demandas Conflitantes. Psicologia\& Sociedade; v. 19, n. 1, 77-84, jan/abr. 2007.

JULIEN, P. A. Empreendedorismo regional e a economia do conhecimento. Tradução Márcia Ferreira Salvador. São Paulo: Saraiva, 2010. 
KNUDSON, W.; WYSOCKI, A.; CHAMPAGNE, J.; PETERSON, H. C. Entrepreneurship and Innovation in the Agri-Food System. American Journal of Agricultural Economics, v. 86, n. 5, p. 1330 -1336, 2004.

MACHADO, H. V.; ST-CYR, L.; MIONE, A.; ALVER, M.C.M .O processo de Criação de Empresas por Mulheres. RAEeletrônica, v.2, n.2, jul/dez, 2003.

MASLOW, A. H. Motivation and personality. New York: Harper \& Brothers, 1954.

MELLO, S. C. B.; LEÃO, A. L. M. S.; PAIVA JÚNIOR, F. G. Competências Empreendedoras de Dirigentes de Empresas Brasileiras de Médio e Grande Porte que Atuam em Serviços da Nova Economia. RAC, v. 10, n. 4, out/dez.p. 47-69, 2006.

MIAO, Q.; LIU, L.A Psychological Model of Entrepreneurial Decision Making. Social Behavior and Personality, v. 38, n. 3, p. 357-363, 2010.

MOTTA, J.; TREVISAN, M. Perfil de empreendedores: Associação de jovens empresários de Santa Maria/RS. SEMEAD, 7., São Paulo, Anais... São Paulo, 2004.

NOVAES, M. B. C.; GIL, A. C. A pesquisa-ação participante como estratégia metodológica para o estudo do empreendedorismo social em administração de empresas. Revista de Administração Mackenzie, v. 10, n. 1, 2009.

RELPH, E. Place and placelessness. London: Pilon, 1976.

SANTOS, P. C. F.; MINUZZI, J.; CRUZ, N. J. T. Propensão e Potencial Empreendedor em Estudantes de Farmácia. In: EGEPE - Encontro de Estudos sobre Empreendedorismo e Gestão de Pequenas Empresas. Recife, Anais... Recife, 2010.

SELLTIZ, C.; JAHODA, M.; DEUTSCH, M.; COOK. S. W. Métodos de pesquisa nas relações sociais. São Paulo: EPU/EDUSP, 1972.

SERVIÇO BRASILEIRO DE APOIO ÀS MICRO E PEQUENAS EMPRESAS - SEBRAE. Estratégia: planeje para começar com sucesso - O que é preciso saber antes de iniciar um empreendimento. Brasília: SEBRAE, 2004.

SHAMAI, S, Sense of place: An empirical measurement. Geoforum, v.22, p.347-358, 1991.

SOARES, M. A. F.; MACHADO, H. P. V. Jovens empreendedores: perfil, dificuldades na gestão e perspectivas dos empreendimentos. In: EGEPE - Encontro de Estudos sobre Empreendedorismo e Gestão de Pequenas Empresas. 4. 2005, Curitiba, Anais... Curitiba, p. 305-312, 2005.

SOUZA, C. Você é do tamanho dos seus sonhos. São Paulo: Gente, 2003.

TIMMONS, J. A. New venture creation: entrepreneurship for the 21st century. 4. ed. Boston: Irwin, 1994.

TRUTMAN, N. Manual para Sonhadores. São Paulo: LeYa do Brasil , 2013

TUAN, Y.F. Rootedness versus sense of place. Landscape, v. 24, n. 1, p. 3-8, 1980.

VICENZI, S. E. Fatores motivadores do empreendedorismo na decisão de conteúdo estratégico nas empresas da cidade de Foz do Iguaçu. Dissertação (Mestrado em Administração). Universidade Federal do Paraná, Curitiba, 2011.

WILLIAMS. D. R.; ROGGENBUCK, J. W. Measuring place attachment: some preliminary Results. In: J. GRAMANN, J. (Orgs.) Proceedings of the third symposium on social science in resource management. College Station: A\&M University, 1990. 